\title{
XR-Immersive Labs Improve Student Motivation to Learn Kinesiology
}

\author{
Tumay Tunur $^{1 *}$, Sean W. Hauze ${ }^{2}$, James P. Frazee ${ }^{2}$ and Paul T. Stuhr ${ }^{1}$ \\ ${ }^{1}$ Kinesiology, California State University San Marcos, San Marcos, CA, United States, ${ }^{2}$ InstructionalTechnology Services, San \\ Diego State University, San Diego, CA, United States
}

\section{OPEN ACCESS}

Edited by: Maria Limniou, University of Liverpool,

United Kingdom

Reviewed by:

Aryabrata Basu,

Emory University, United States

Simon M. Su,

United States Army Research Laboratory, United States

*Correspondence:

Tumay Tunur

ttunur@csusm.edu

Specialty section:

This article was submitted to Virtual Reality and Human Behaviour,

a section of the journal

Frontiers in Virtual Reality

Received: 02 November 2020 Accepted: 03 February 2021

Published: 29 April 2021

Citation:

Tunur T, Hauze SW, Frazee JP and Stuhr PT (2021) XR-Immersive Labs Improve Student Motivation to Learn Kinesiology.

Front. Virtual Real. 2:625379. doi: 10.3389/frvir.2021.625379
Kinesiology is an inherently spatial discipline, both physically and visually. The use of extended reality-immersive lab activities may enhance students' motivation to learn by enabling students to interact with visual content and illustrate and demonstrate kinesiology content and concepts. Using an instrumental case study method, this article assesses the use of extended reality immersion across three semesters of an upper division kinesiology course focused on motor control. This is a unique approach because it blends established physical motor control and biomechanical data collection techniques with emerging virtual reality technology to enhance-rather than replace - the lab experience. The effectiveness is measured via an experimental design to contribute to the small, but growing, body of knowledge on the efficacy of immersive learning.

Keywords: virtual reality, extended reality, education, motivation, learning, laboratory

\section{INTRODUCTION}

Extended reality (XR) refers to an array of computer-generated immersive environments including augmented reality (AR), virtual reality (VR), and mixed reality (MR). In other words, XR is the umbrella that brings together these various environments in a reality continuum under one term. The continuum, dubbed as the reality-virtuality continuum (Milgram et al., 1994), encompasses the range of immersive environments. Immersive experiences, within this continuum, are changing how we learn and experience the world. Augmented reality enhances the user's current state of presence by superimposing images, video, or graphics over the user's natural environment. On the other end of the continuum, virtual reality is a way to immerse users in an entirely virtual world that is generated by computer technologies (Hartley et al., 2015). For these immersive worlds, it is conceivable to design and create any object, location, or organism one can imagine with possibilities being endless (Janssen et al., 2016). The center of the continuum is mixed reality (MR). Also known as spatial computing, MR integrates virtual content into the context of the physical environment using infrared-scanning hardware mounted on the front of a head-mounted display (HMD).

XR training has been shown to improve learner's performance across an array of instructional simulations. From Walmart to PricewaterhouseCoopers, the business community is increasingly reliant upon XR to deliver high-quality immersive simulation training to improve employee performance at scale. Walmart recently purchased 17,000 Oculus Go VR headsets to expand upon their successful pilot $(\mathrm{n}=150,000)$ of high-stakes training scenarios, such as the chaotic shopping environment that can occur on Black Friday. In partnership with Strivr-a VR development company, cofounded by Stanford University Virtual Human Interaction Lab director, Jeremy Bailenson-Walmart determined that the VR training modality resulted in a higher rate of knowledge retention, and increased employee satisfaction among Walmart Associates (Klotz, 2018; Walmart Case Study, 2018). A similar study conducted by PricewaterhouseCoopers in 
2020 concluded that VR-trained learners were more focused and more emotionally connected to the training material than their classroom-or e-learning-trained peers-resulting in a $35 \%$ improvement in the ability to act on what they learned following the VR session than traditional training modalities (Eckert and Mower, 2020). The results of these studies illustrate the growing body of research, demonstrating the benefits of XR training for improved performance.

Furthermore, XR-immersive education is considered as a field with massive potentials and has evolved from "concept phase" to "implementation phase," for which pragmatic application is now being used in a variety of contexts. XR-immersive education has clear advantages in teaching both theoretical knowledge and practical skills than the traditional methods. It improves students' ability to materialize abstract problems and allows for increased opportunities for hands-on learning. Moreover, XR-immersive learning increases students' sense of engagement by making the experience immersive, exciting, intriguing, and active. Instructors can customize virtual classrooms to have content-specific information and resources continuously available in the virtual environment (O'Connor and Domingo, 2017; Domingo and Bradley, 2018). Therefore, students can experience impractical or dangerous science experiments regardless of the logistical, geographical, or accessibility issues they would have experienced in person (Koglbauer, 2015; Urso and Fisher, 2018).

An example of the use of XR immersion to increase access to otherwise restrictive learning experiences is virtual worlds enable the ability to place students from a traditional classroom, directly into gross labs where they can dissect human bodies or in a war setting for PTSD treatment training. Virtual worlds can also provide virtual tours of the real world and take them to various countries to introduce the students to different cultures for inclusion and diversity training (Argles et al., 2015; Kim and Ke, 2016). In addition, the students can experience high-risk situations (i.e., experimenting with dangerous chemicals and first-responder cases), improbable or impossible scenarios (i.e., no gravity environments, the Solar System), or visualize complicated theoretical constructs (i.e., photon movement). Not only the students can immerse themselves inside these simulations but also they can get immediate feedback on any interactions they may have with the environment. Students can gain experiential, student-centered, cognitivist, and constructivist learning experiences by exploring and interacting with these complex and immersive environments at their own pace (Kluge and Riley, 2008).

The ability to practice real-world scenarios in studentcentered environments empowers students to develop mastery of the content without risk, thus enabling students to engage in both mastery learning and deliberate practice (Bloom, 1968; Ericsson et al., 1993). Through this deliberate and iterative practice, students can attain an enduring understanding of the content. Heighten competence builds student confidence, which is shown to be the key component of student motivation to learn (Keller, 1987). Despite some efforts of utilizing XR immersion in $\mathrm{K}-12$ education, research on $\mathrm{XR}$ immersion in postsecondary environment is very limited (Rae and Samuels, 2011; Riva, 2016;
Hauze et al., 2019; Bennett and Saunders, 2019; Radianti et al., 2020). While XR-immersive education was shown to be at least as equally effective in the acquisition and retention of the material as traditional education, the use of XR provides a more positive learning experience and increases student motivation to learn (Stepan et al., 2017; de Vries and May, 2019; Sattar et al., 2019).

The (blinded) lab was developed at an institution to enable students' experience scenarios otherwise limited or impossible in a traditional learning environment and to increase students' motivation to engage in a hands-on learning environment. Given the complexity of the content covered and the requisite student learning outcomes in kinesiology courses, students are engaged in lab activities to apply these concepts through handson exercises. However, limitations of space and expensive lab equipment result only one or two students, at a time being, able to engage with the exercise while the other students wait idly. In addition, the high cost of kinesiology research-combined with the limitation of lab space-results in difficulty for undergraduate students to design and execute their own experiments. Our study helps fill this gap in education research in XR-immersive labs that utilize HMDs (Radianti et al., 2020) and explores student motivation to learn in response to improving the number and quality of XR-immersive content across multiple semesters.

The theoretical framework utilized in this study is the John Keller's Attention, Relevance, Confidence, and Satisfaction (ARCS) model of student motivation to learn (1987). Students' motivation to learn is a critical component of engaging students in the learning process. The ARCS model asserts that motivation to learn comprises the degree to which the learner becomes engaged in the learning experience through elements of attention, relevance, confidence, and satisfaction. Keller's research on student motivation to learn indicates each of the four ARCS constructs must be present in order to effectively motivate students in the learning process. To measure the four constructs of the ARCS model (Table 1), Keller (1993, unpublished $)^{1}$ developed the Instructional Materials Motivation Survey (IMMS).

The purpose for this study was to determine the extent to which XR-immersive labs would change the students' perception and motivation toward learning in an undergraduate Motor Control and Learning course. Specifically, the aim of the study was to determine attention, satisfaction, relevance, and confidence of the undergraduate students using the XRimmersive labs-in other words, did students enjoy using XR (i.e., satisfaction), did students feel XR related to the content of the course (i.e., relevance), and did the students feel XR enhanced their learning of the course materials or learning outcomes (i.e., confidence). In an attempt to represent the undergraduate experience using XR-immersive technologies, a mixed methods case study was used to shape the research study.

${ }^{1}$ Keller, J. M. (1993). Manual for instructional materials motivational survey (IMMS).Unpublished. 
TABLE 1 | Constructs of the Instructional Materials Motivation Survey.

Construct

Attention

Relevance

Confidence

Satisfaction
Definition

IMMS survey responses measuring the degree to which the learner found the scenario attention-grabbing IMMS survey responses measuring the degree to which the learner found the scenario relevant

IMMS survey responses measuring the degree to which the learner felt confident while completing the scenario IMMS survey responses measuring the degree to which the learner found the scenario satisfying

\section{MATERIALS AND METHODS}

In an attempt to represent the undergraduate experience using XR-immersive technologies, a mixed methods case study was used to shape the research study. All procedures were approved by the (blinded) Institutional Review Board.

\section{PARTICIPANTS}

A total of 148 participants over the age of $18(\mathrm{~F}=87$ and $\mathrm{M}=61)$, composed of juniors and graduating seniors, were solicited from an upper division undergraduate course entitled Kinesiology 301: Motor Control and Learning at (blinded) University across three semesters. All participants had limited experience (five sessions or less) in using VR prior to the study. Only seven of the participants had experience with the commercially available games used in the current study (e.g., Beat Saber, Job Simulator, and NoLimits 2). No subjects were excluded from data analysis for having difficulty with completing any of the XR-immersive labs. Each participant completed a consent form at the beginning of the semester.

\section{KINESIOLOGY 301: MOTOR CONTROL AND LEARNING}

The overall objective of Kinesiology (KINE) 301 is to develop student understanding of how humans make effective movements. Understanding involves consideration of the requirements for making movements, and the factors that make human movement inherently complex. This includes the physics of segmented systems, the muscles involved in various human movements, the physiological properties of a muscle, and the nervous system processes necessary to enable and constrain movement. KINE 301 content also includes nervous system interaction with musculoskeletal system necessary to achieve high performance. Students' understanding of the dynamic neuro-musculoskeletal interactions necessary for effective movement, involves content encompassing neural networks, spinal cord and brain function, and how human movement is executed. The student learning outcomes of KINE 301 include 1) applying basic principles of segmental mechanics to understand movement, 2) explaining how the brain, spinal cord, and musculoskeletal systems interact to plan, and execute movement using concepts from control systems theory, dynamical systems theory, neuroanatomy, neurophysiology, and psychology, 3) evaluating factors that limit or constrain motor performance, including muscle- and neurophysiological properties, and cognitive information processing, 4) using research findings about motor learning to generate strategies to improve motor performance, including structuring practice, providing feedback, and adapting training to skill level, and 5) evaluating the effects of individual differences on motor control and performance, including differences due to age/development.

\section{STUDY DESIGN}

Case study design provided the researchers a means to collect data in a variety of ways, while attempting to capture the students' perception of using XR-immersive labs. Specifically, instrumental case study methodology was employed to help identify, understand, and refine how the undergraduate students experienced the XR-immersive labs and to what extent did these students attained the intended student learning outcomes of the course (Stake, 1995). In essence, instrumental case study design positioned the focus of the research on collecting data that best represented the use and outcome of the XR-immersive labs. Data collection included both quantitative and qualitative methods for data, which allowed for greater variation across the students' perception of the XR-immersive labs. The varied data collection methods increased the probability to capture a more robust picture of the undergraduates' experience using the XR technology.

\section{XR IMMERSION IN KINESIOLOGY LABS}

The KINE 301 motor control labs were taught in traditional lab setting. In the Spring 2018, piloting of the XR immersion occurred with two XR-immersive lab activities replacing two existing labs in the curriculum (Table 2). The motor control courses in which XR-immersive labs were implemented included Fall 2018, Spring 2019, and Fall 2019. The immersive motor labs were delivered via the following XR technologies: HTC Vive, Oculus Rift, Microsoft HoloLens, Virtualizer Locomotion Platform for VR, and a Wii Balance Board. The following games or applications were used for XRimmersive labs:

1. Intro to VR Lab: Job Simulator (Owlchemy Labs)

2. Balance Lab: NoLimits 2 (Mad Data GmbH \& Co. KG)

3. Upper body Mobility Lab: Reaching Task App [developed by (blinded), Figure 1]

4. Learning and Memory Lab: Beat Saber (Beat Games) 
TABLE 2 | XR immersion across semesters.

\begin{tabular}{|c|c|c|c|c|}
\hline XR Immersion & $\begin{array}{c}\text { Spring } \\
2018(N=33)\end{array}$ & Fall $2018(\mathrm{~N}=32)$ & Spring 2019 ( $N=52)$ & Fall $2019(\mathbf{N}=64)$ \\
\hline \multirow[t]{6}{*}{ Addition of XR-immersive labs } & 1. Intro to VR & 1. Intro to VR & 1. Intro to VR & 1. Intro to VR \\
\hline & 2. Balance & & 2. Balance I & 2. Balance I \\
\hline & & & 3. Balance II & 3. Balance II \\
\hline & & 2. Balance & 4. Upper body mobility I & 4. Upper body mobility I \\
\hline & & & & 5. Upper body mobility II \\
\hline & & $\begin{array}{l}\text { 3. Upper body } \\
\text { mobility }\end{array}$ & 5. Upper body mobility II & 6. Learning and memory \\
\hline \multirow[t]{3}{*}{$\begin{array}{l}\text { Modification to existing } X R \\
\text { labs }\end{array}$} & $\mathrm{N} / \mathrm{A}$ & $\mathrm{N} / \mathrm{A}$ & $\begin{array}{l}\text { 1. Added additional experimental VR } \\
\text { conditions to balance lab }\end{array}$ & $\begin{array}{l}\text { 1. Added additional experimental VR conditions } \\
\text { balance lab }\end{array}$ \\
\hline & & & $\begin{array}{l}\text { 2. Added AR/NR comparison in the upper } \\
\text { body mobility lab }\end{array}$ & \\
\hline & & & $\begin{array}{l}\text { 3. Increased the activity time for each student } \\
\text { 4. Included additional parameters }\end{array}$ & $\begin{array}{l}\text { 2. Added new experimental VR group to upper } \\
\text { body mobility lab }\end{array}$ \\
\hline Instructional Materials & $\mathrm{N} / \mathrm{A}$ & Collected $(\mathrm{N}=23)$ & Collected $(\mathrm{N}=52)$ & Collected $(\mathrm{N}=60)$ \\
\hline \multicolumn{5}{|l|}{ Motivation Survey } \\
\hline Student Reflection & $\mathrm{N} / \mathrm{A}$ & Collected $(\mathrm{N}=31)$ & $\mathrm{N} / \mathrm{A}$ & $\mathrm{N} / \mathrm{A}$ \\
\hline
\end{tabular}

\section{SAMPLE LAB ACTIVITY: BALANCE LAB}

In the traditional KINE 301 setting, the balance lab has been delivered by having the students stand still on a force platform (Bertec) on one foot for $30 \mathrm{~s}$ for each condition: eyes-open and eyes-closed.

In the XR-immersive version of this lab, students were asked to stand still on both feet on a force platform wearing a VR headset: eyes-open, eyes-closed, and roller coaster. In the eyes-open condition, the students were presented with a stationary scene. In eyes-closed condition, the students were asked to close their eyes and the headset was turned off. In roller coaster condition, they watched a simulation of a roller coaster in VR (NoLimits 2). In both cases, the students calculated mean postural sway range and velocity using force platform data.

\section{DATA COLLECTION}

After the final immersive lab content of the Fall 2018 semester, the students were asked to write a reflection in response to the following probing questions about the use of XR immersion in the labs:

1. What were your expectations from VR? Did you have any positive/negative emotions toward using the equipment? Please explain.

2. How quickly were you able to adapt/adjust to the VR environment?

3. How effectively did you accomplish the task given? What were, if any, the limitations that you felt were present when using the VR simulation?

4. How much did your experience in the VR simulation seem consistent with a real-world experience?

5. Did you experience cyber-sickness (i.e., nausea and dizziness)?
6. Did you feel confusion or disorientation either when you were wearing the headset, or after you took them off?

In addition to the semistructured reflections, the students were asked to anonymously complete an online version of Keller's Instructional Materials Motivation Survey (IMMS; Cook et al., 2009) in order to assess the students' motivation for learning after the final immersive lab content of the semester in the Fall 2018, Spring 2019, and Fall 2019. The IMMS was created to measure and identify gaps in students' motivation to learn, relative to the use of self-directed learning materials. The IMMS comprises 36 Likert scale questions which prompt users to rate their response to each item such that $1=$ strongly disagree with the statement, $2=$ disagree with the statement, $3=$ neither agree nor disagree with the statement, $4=$ agree with the statement, and $5=$ strongly agree with the statement. The 36 items were mapped to the four constructs of the ARCS model including attention (12 questions), relevance ( 9 questions), confidence (9 questions), and satisfaction (6 questions). The question ratings in each construct were averaged for a construct score. The mean of four construct scores was used for the overall score.

\section{ANALYSIS}

Regarding the reflexive analysis of the qualitative data, provenances were used to track the source location of each datum. The tracking of the data was important to ensure integrity and trustworthiness of the emerging themes and qualitative assertions being reported. Additionally, by using provenances to track the source of the data, the researchers were able to determine whether the themes being discovered were consistent across the majority of the participants in the study. The following provenance labels were used for the lab reflections: semester and year, question, and student. For example, (F18, Q5, and S11) would represent lab reflections that were completed during Fall 2018, question 5, and by 


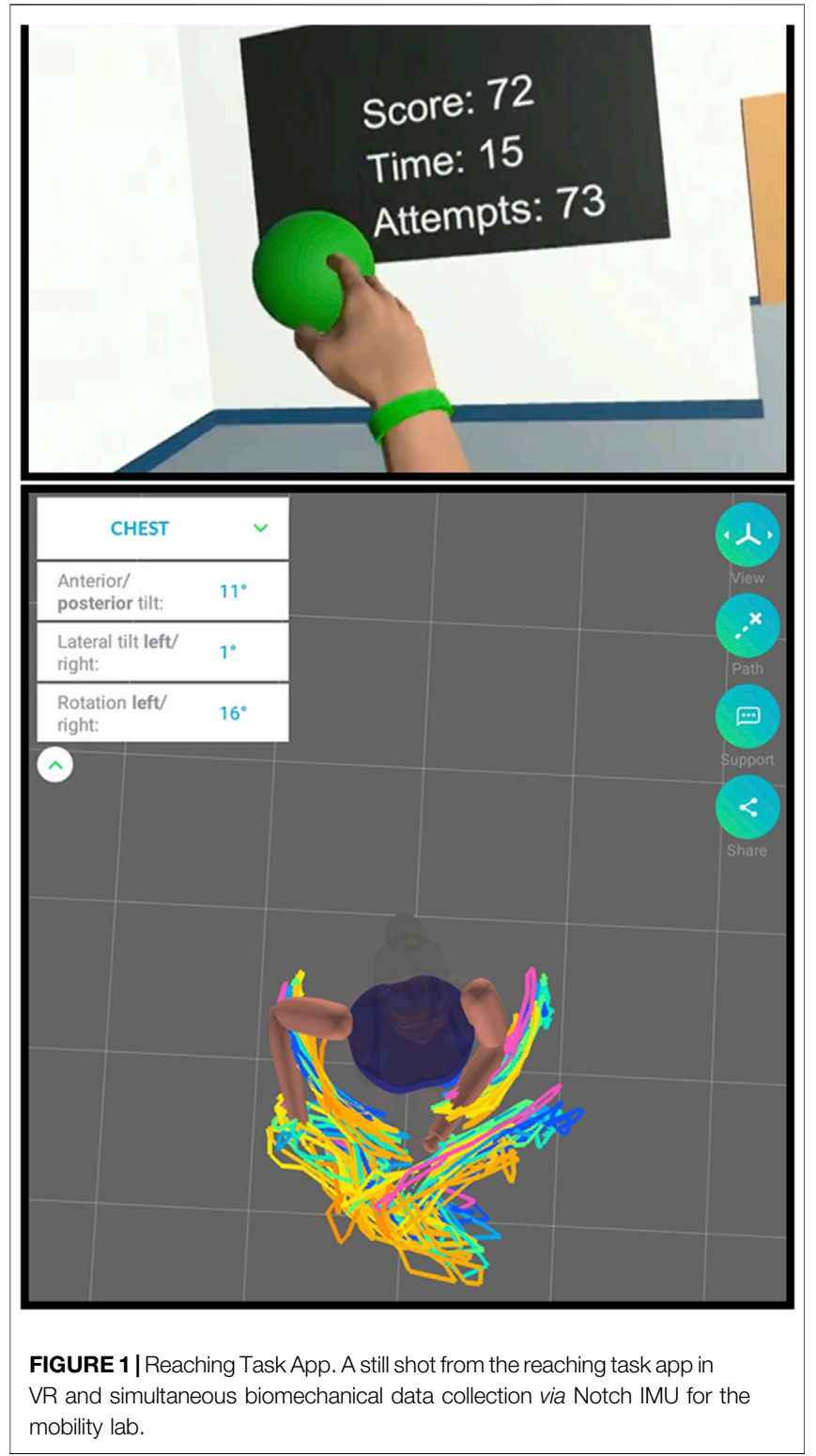

student 11. However, (Sp19, Q5, and S7) would indicate lab reflection data from Spring 2019, question 5, and student 7. A quasi-inductive approach (Jensen, 1998) was used, which allowed the selection of the ARCS model constructs as predetermined themes before the sampling and coding process.

The data analysis consisted of open and selective coding (Corbin and Strauss, 2015). First, data were transcribed, and initial labeling of data occurred (i.e., open coding). The second step of the qualitative analysis included rereading the transcripts to confirm, reject, or modify the initial themes and assertions (i.e., selective coding). In addition, during the selective coding step, transcripts with the themes/assertions were read by another higher education colleague (i.e., peer debrief) to ensure the confirmability of the coding/analysis process.

The Kruskal-Wallis test was used to compare IMMS scores across semesters. The post hoc analysis was completed using the
Dunn's multiple comparisons test. $p<0.05$ was considered significant.

\section{RESULTS}

In this study, we integrated XR-immersive labs to a kinesiology course: Kinesiology 301: Motor Control and Learning. Over the semesters, we increased the number of lab modules that include $\mathrm{XR}$ content and pedagogy and modified the existing ones based on student and instructor feedback. Based on the analysis of student reflections and the IMMS scores, XR-immersive labs were seen by the students as a unique aspect to learning of the KINE 301 course. Altogether, this study supports the claims about the effectiveness of XR-immersive education on students' motivation to learn (Hauze et al., 2019) and refutes the notion of immersive experiences distracting students from the learning task (Jensen and Konradsen, 2018).

\section{STUDENT FEEDBACK}

By answering probing questions, students were able to reflect on and provide feedback regarding their experience with XRimmersive labs and the factors that impacted their motivation to learn course material. Predetermined themes helped guide the data analysis process using the constructs of the ARCS model: attention, relevance, confidence, and satisfaction. Analyses of the reflections revealed student perception regarding the ARCS model constructs was enhanced with the use of XRimmersive labs.

\section{ATTENTION}

To gain the students' attention in a subject matter, the pedagogical tools should allow for perceptual arousal or inquiry arousal. Perceptual arousal is defined as gaining the students' attention by surprise, doubt, or disbelief. Students reported that XR-immersive labs were perceptually arousing: "Overall, $\mathrm{XR}$ is a lot more exciting than traditional labs because the interaction is more stimulating" (Q4, S1). However, the inquiry arousal is achieved when the students' curiosity is encouraged by providing opportunities of problem solving. Students reported that XR-immersive labs stimulated their inquiry-based learning:

\section{I truly enjoy having XR-integration labs because I think $X R$ brings more excitement and a different learning perspective to a lab setting. Before taking this course (KINE 301), I had very little knowledge of XR and now I find myself being more interested in researching how $X R$ can help with rehabilitation (Q2, S6).}

XR-immersive activities were seen to peak student interest and their arousal toward engagement in lab. "Many of the XR labs have been engaging ... I am excited to learn from our next XR 
labs and develop a better understanding of how XR technology improves motor performance and skills" (Q5, S6). In summary, $\mathrm{XR}$-immersive labs were perceived as novel/unique learning tools (i.e., perceptual arousal) and able to stimulate students' curiosities/interests (i.e., inquiry arousal).

\section{RELEVANCE}

An important element of incorporating a technological instrument such as $\mathrm{XR}$ to a course is how relevant the students perceive the tool to be for their learning. Therefore, it is crucial to present the objectives of using such technologies and clear instructions on how to utilize the instrument during the instructional tasks/lesson. The students were able to connect the XR-immersive labs to content knowledge covered in KINE 301:

When it was mentioned that we would be using XR, I was ecstatic because I thought it was going to be so cool to learn how XR could be integrated in the ideas we learn in class. I really enjoy having this integration to the labs because it gives a different perspective on learning concepts such as center of pressure, where it would not have been understood as well in just opening and closing one's eyes. The roller coaster XR showed how our brain will basically trick our body into thinking that we are unable to balance on one leg and it did (Q1, S31).

Students also appreciated the technological literacy they have gained through XR immersion and its possible advantages to their future careers:

I do enjoy having the XR integration labs. I think, in this day it is important to have an understanding of technology as it may be used in the future in our field. It is also important to understand what is being developed and potentially integrated into rehabilitation/ clinical settings as it will affect me in the future (Q1, S10).

Students broadened their perspective and started understanding implications of XR technologies beyond simply recreational usage:

Yes, I absolutely love experiencing XR in labs. I always related it to something that could only be used in games, but it has really opened up my eyes to how it can be integrated in kinesiology and even (physical) therapy (Q1, S12).

Furthermore, students were able to practice their skills relevant to the course using more real-life examples through hands-on experiences, "I believe by integrating VR into the labs, it gives me more of a hands-on understanding of the concepts" (Q2, S18). Finally, the students predicted that XR will be widely accepted and utilized in Kinesiology and related fields in the near future, "I think Virtual Reality is something that will be used a lot in the future for video games and for exercise or (physical) therapy" (Q1, S5). Students believed that the XR immersion was related to important personal and professional goals or motives. Overall, XR was seen as an appropriate way to deliver course material in KINE 301. The students were able to connect the XR technology to KINE 301 content, associate its benefit toward their future careers, and connect its importance while practicing hands-on real-world examples.

\section{CONFIDENCE}

Even though students find the material interesting and relevant, if they feel as though they will not be successful in the course using the XR technology or learning the content in virtual environments, then this will diminish their motivation to learn. Therefore, it is extremely important that the students feel a sense of confidence that utilizing XR-immersive labs will help them achieve success in the course, "It was a nice way to be able to experience the things we otherwise would not be able to in real life scenarios, and I think it is very beneficial in the learning process" (Q1, S6). Elements of XR that are inherently related to their success in completing the labs such as level of interaction with the virtual environment, and visual and auditory feedback were also identified in student reflections:

I think the integration of XR into the labs supports course
material by bringing to life concepts and ways of thinking
about movement. When comparing different VR
simulations, like that of the office environment to the
roller coaster, concepts such as open and closed
environments are made clearer. Additionally, I have
been able to better understand the various factors that
influence balance and stability, like proprioception and
visual and auditory stimuli. This was evidenced in the
roller coaster simulation as the noises produced by the
roller coaster seemed to affect my balance as well
(Q2, S2).

Students also commented on how XR improves their learning of the material by providing experiences, otherwise would not be available in traditional labs, enabling active engagement with the content and increasing their retention of the material:

One benefit to understanding lab material is that we actually get to move our bodies in ways we typically would not without VR. The material that we are learning is very complex and it is beneficial to have such an active experience compared to the typical passive experience. I always prefer a hands-on approach compared to listening to someone talk about movement, but rather experiencing movement on your own. Using VR helps me remember lab better because it was such an exciting visual that it is hard to forget (Q2, S15).

One student gives a specific example of how XR is connected to their success in learning specific course material: 
The benefits of having XR integration into labs to $m y$ understanding of the material is that it allows me to learn application that would not be accessible in class. For example, during our balance lab we were able to test our balance with the VR, while visualizing a roller coaster ride. It allowed for more variables in the experiments, which enhances the learning processes (Q2, S3).

Another student explains how immersive and realistic such experiences can be perceived and consequently deepen student learning:

The benefits of having XR in our labs allows us to experience it first-hand and understand the lab material on a deeper level. For example, doing the second part of the postural balance lab (that involved the roller coaster). Most people allowed invalid visual information (when wearing the VR headset) to trick their mind and body into thinking that they are experiencing a roller coaster ride. The visual input of the roller coaster makes our body adjust to the feeling of what a roller coaster would feel like. As a result, in real life, most of us had lost most, if not all, stability while standing on the balance board (Q2, S21).

This student provides a very detailed account in their reflection about a more enduring understanding of course material due to the XR technology.

Overall, students perceived the XR environment helpful in comprehension of lab material, "I think (XR) provides a great way of understanding motor control and development. I cannot think of a better way to demonstrate and understand the concepts we are speaking about in class" (Q4, S10).

\section{SATISFACTION}

Joy of learning can come from intrinsic or extrinsic factors. Nonetheless, they are both directly related to the level of motivation. Students highlighted in their reflections how enjoyment of the XR labs enhanced their engagement in the course material:

I do enjoy having XR integrated into our labs. I think it is a fun and interesting way to be engaged in what we are learning. It gets me excited to take part in the lab while also familiarizing myself with XR (Q1, S11).

Others appreciated gaining perspective on the application of XR to the Kinesiology field, "Yes, I do enjoy the XR integration to labs. The XR aspect of the lab brings a new outlook on how Kinesiology can be applied" (Q1, S3). Moreover, students enjoyed the immersive nature of the XR environments, "Yes, I enjoy having XR integration to lab because it brings a unique aspect to learning. I have never used VR before, and I was amazed at how real it felt when I was using the VR" $(\mathrm{Q} 1, \mathrm{~S} 8)$. It is clear from students' reflections that the level of enjoyment they had for the XR-immersive labs increased their interest and anticipation for the upcoming labs:

I can remember every lab we have done, because each lab had a greater purpose, and I enjoyed every single lab. Every lab gave me a greater appreciation for XR, and now when I hear we are doing XR labs, I look forward to our lab days (Q4, S1).

Finally, the students perceived this as a unique experience they would not be able to get elsewhere appreciating the learning opportunities provided for them, "I really have enjoyed virtual reality being such an integral component of our laboratories. It is a very novel experience that I would not be able to experience anywhere else but the lab ..." (Q1, S24).

With regard to satisfaction, students generally said that XRimmersive labs were "more engaging", "more fun", and "enhance (ed) their learning". XR was perceived by the students as an enjoyable teaching method for lab which was perceived as a motivating factor toward student engagement of course tasks and learning objectives.

Students outlined how XR-immersive labs increased their motivation to learn by mentioning all four constructs of the ARCS model:

I have found that I learn the material much better (attention), because I enjoy doing the XR labs (satisfaction). Since I enjoy doing the XR labs, this makes me more motivated to learn the material presented in both lab and lecture (relevance). Regarding my future, I can definitely integrate some form of XR into my career (confidence) (Q2, S9).

Most of the students commented on how XR-immersion can benefit their career goals in addition to their education in the field of Kinesiology:

I think having XR integration in our labs helps us better understand course material because we are able to get hands-on experience (relevance) and see how motor control applies to the XR world (relevance). XR integration benefits our class because we can learn and have fun at the same time (relevance). When students find a lab as a fun activity (satisfaction) we are more inclined to learn the material and apply it (confidence). I believe XR may be an option of rehabilitation in my future career. I find this course and the labs meaningful (relevance) because I can apply what I've learned in my future career (confidence). My goal is to become an Occupational Therapist and I think $X R$ can be a treatment/rehabilitation option for sure (relevance). The benefits of being able to use the XR is that we, the students, can actually put our feet in someone else's shoes and understand how a possible rehabilitation procedure may be a challenge for a patient (confidence). I can take this information with 
TABLE 3 | IMMS Scores Across Semesters.

\begin{tabular}{|c|c|c|c|}
\hline IMMS scores & Fall 2018 & Spring 2019 & Fall 2019 \\
\hline \multicolumn{4}{|l|}{ Overall ${ }^{\star}$} \\
\hline Mean \pm SD & $3.87 \pm 0.64$ & $4.11 \pm 0.48$ & $4.23 \pm 0.51^{\#}$ \\
\hline Minimum & 2.67 & 2.91 & 2.94 \\
\hline Maximum & 4.94 & 4.94 & 4.94 \\
\hline \multicolumn{4}{|l|}{ Attention } \\
\hline Mean \pm SD & $4.05 \pm 0.79$ & $4.31 \pm 0.49$ & $4.43 \pm 0.54$ \\
\hline Minimum & 2.91 & 2.82 & 3.08 \\
\hline Maximum & 5.00 & 5.00 & 5.00 \\
\hline \multicolumn{4}{|l|}{ Relevance* } \\
\hline Mean \pm SD & $3.86 \pm 0.58$ & $4.04 \pm 0.60$ & $4.21 \pm 0.58^{\#}$ \\
\hline Minimum & 2.89 & 2.78 & 2.89 \\
\hline Maximum & 4.89 & 5.00 & 5.00 \\
\hline \multicolumn{4}{|l|}{ Confidence* } \\
\hline Mean \pm SD & $3.53 \pm 0.68$ & $3.88 \pm 0.54$ & $3.91 \pm 0.57$ \\
\hline Minimum & 2.11 & 2.67 & 2.67 \\
\hline Maximum & 4.89 & 4.89 & 5.00 \\
\hline \multicolumn{4}{|l|}{ Satisfaction* } \\
\hline Mean \pm SD & $4.06 \pm 0.80$ & $4.15 \pm 0.55$ & $4.39 \pm 0.64$ \\
\hline Minimum & 2.33 & 3.17 & 2.17 \\
\hline Maximum & 5.00 & 5.00 & 5.00 \\
\hline
\end{tabular}

${ }^{*} \mathrm{p}<0.05$, Kruskal-Wallis test.

\# $p<0.05$ compared to Fall 2018, Dunn's multiple comparison test. p $<0.05$ compared to Spring 2019, Dunn's multiple comparison test.

me in the future and use it to help any potential patients be more in touch with themselves as I have personally be able to experience what they may be feeling (confidence) (Q2, S7).

Students linked their satisfaction from XR immersion to how confident they feel in learning the course material and how relevant they believe it is for their future professional goals:

I think that integrating XR into our labs was a genius decision (satisfaction). I have felt a sense of accomplishment when completing the activities (confidence). I think the XR world has a lot to offer and studies have shown how XR in rehabilitation and therapy is effective (relevance) $(\mathrm{Q} 5, \mathrm{~S} 6)$.

Overall, from the student reflections, there emerged a connection between the XR-immersion and the four constructs associated with the ARCS model. The findings from the qualitative data corpus represent the participants established pattern to recognize and connect their experiences using XR technology with the constructs of attention, relevance, confidence, and satisfaction. The students in KINE 301 found the XR-immersion to be a surprisingly novel, yet an applicable way to enhance hands-on learning of course objectives. Students acknowledged that XR-immersion was a fun and exciting technology that was relatable to the field of Kinesiology and suited for content acquisition connected to their future career paths. The data that was discovered from the student reflections signifies that XR-immersion is a plausible technological tool to enhance motivation in studying the content of KINE 301.

\section{STUDENT ATTITUDES}

Table 3 exhibits mean, minimum, and maximum scores for the four IMMS constructs and the overall score. Overall, the students' motivation to learn has improved across semesters, complementary to the findings from analyses of the student reflections. In particular, improvements on confidence, relevance, and satisfaction mean scores were significant. Finally, Figure $\mathbf{2}$ displays each student's individual scores. Distribution of the data suggests that more students showed higher motivation to learn in F2019 than in F2018.

\section{DISCUSSION}

According to the 148 responses from students across three semesters, their motivation levels to learn kinesiology using XR-immersive labs were higher than IMMS averages seen in traditional courses across disciplines in the literature which are generally between 2-4 (Huang and Hew, 2016). Three out of four individual construct scores (attention, relevance, and satisfaction) and the overall score from the final semester were higher than 4.0, indicating that the XR-immersive labs were motivating students to learn kinesiology. These findings, aligned with similar studies showed high motivation level of students to learn in courses using novel teaching methods (Loorbach et al., 2015; Annamalai, 2016; Chang et al., 2019). Importantly, with the increasing XRimmersive content across semesters, the students' motivation levels were improved further. Additionally, the data that was discovered from the student reflections compliments the IMMS findings and signifies that XR is a plausible technological tool to enhance motivation in learning the content of KINE 301.

Even though, our study focused on learning kinesiology content, our findings could inform teaching practices in STEM which are grounded in similar learning theories such as cognitivism, experientialism, and connectivism. XR-immersive labs improved motivation to learn kinesiology by providing a virtual environment, where discovery of knowledge is encouraged. This fits in with the view of cognitivism that learning is active, goal-oriented, and involves discovery of new information that builds on to an existing body of knowledge (Shuell, 1986). Our qualitative findings suggested that students demonstrated elevated attention in the subject matter due to perceptual and inquiry arousal. Hence, XR-immersive labs can strengthen cognitivist learning design that involves problemsolving, concept formation, and information processing (Dede, 2008).

Experientialism describes a type of learning that results from grasping and transforming of experiences (Kolb, 1984). In XRimmersive labs, students experience a variety of conditions surrounding a hypothesis. They not only collect data using traditional kinesiology lab equipment, but also, kinesthetically, and visually explore each condition in an immersive environment allowing them to build confidence in the content knowledge and skill proficiency in their field.

Lastly, a newly introduced learning theory, connectivism, refers to exploring learning in a digital age. This theory 

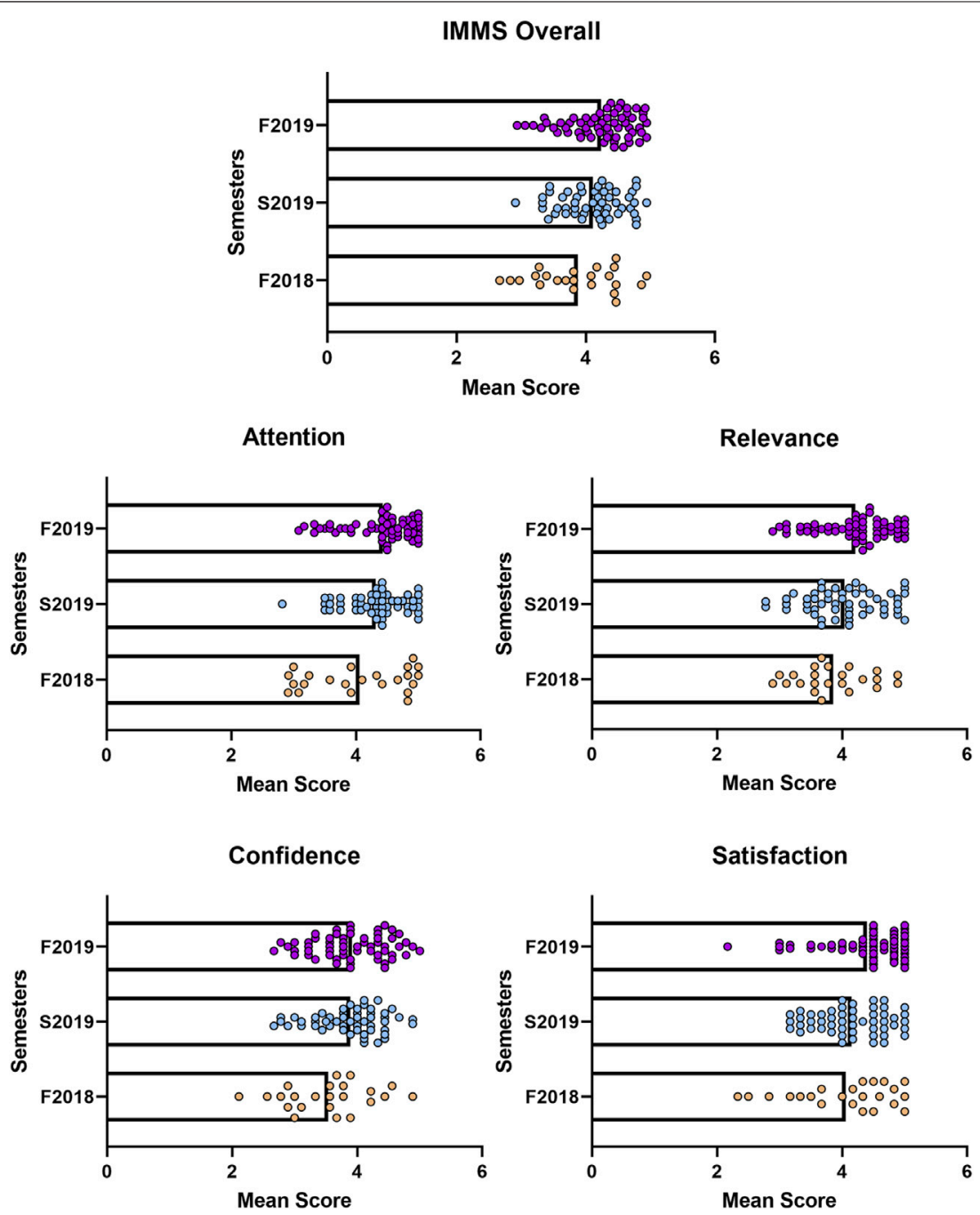

FIGURE 2 | IMMS Scores. Graphs represent IMMS scores for each construct and the overall score across semesters for each student.

suggests that learning is lifelong, and therefore, continued after graduation by using new technology tools (Siemens, 2005). As evident from students' comments about "relevance" of XRimmersive labs, having gained technological literacy and experience in using XR equipment and software can aid students in their future careers.

Self-learning effectiveness is correlated with students' satisfaction and sense of accomplishment in the learning experience (Keller, 1993). Students described XR-immersive labs as "fun," "engaging," and "learning enhancing." Overall, we concluded that XR-immersive labs produced learning interest.

Significance of our study is that it (1) takes XR-immersion from being solely simulation-based to experiential and (2) utilizes high-end and immersive XR equipment. Current literature on XR in education focuses on $2 \mathrm{D}$ virtual environments that are often viewed from a monitor (Chavez and Bayona, 2018). By using XR as a way to experience the paradigms rather than viewing a simulation of content gives more possibilities for instructors, who may not have access to relevant virtual content for their labs.
Furthermore, the use of immersive XR equipment distinguishes our study from the others in a way that immersion can have positive impact on presence, engagement, and learning outcomes (Jensen and Konradsen, 2018).

\section{CHALLENGES STUDENTS ENCOUNTERED}

One of the challenges we faced during XR-immersion was the limited XR equipment available in our labs. Insufficient quantity of virtual reality headsets resulted in high waiting times for students. Over the semesters we were able to increase the amount of equipment in our labs. Additionally, we started to divide the students into groups of four, and giving separate roles to each student within the group (e.g., spotting the person wearing the headset, recording data, and assisting in completion of the task by providing verbal feedback to VR user). These strategies solved the problem by reducing inactive time of students 
and enabled them to be engaged with the experiments, even outside of the XR activity.

Another challenge we ran into was the lack of available content in XR for kinesiology education. We adapted commercially available games into experimental procedures and developed our own applications over the last year. As developing content is very time and labor intensive, we see this as one of the biggest obstacles in promoting the use of XR currently in kinesiology education.

\section{LIMITATIONS}

One limitation of this study is the lack of data on student motivation for kinesiology learning in Kinesiology 301 course without the XR immersion. Even though we are able to see the improvements in student motivation from minimal implementation in the first semester to the final semester, the claims made in the study could have been stronger with inclusion of pre-XR-immersion survey data, or of a control group.

\section{FUTURE DIRECTIONS}

Our study demonstrates the effectiveness of XR-immersive labs on student motivation, especially when a high number of XRimmersive activities are used (i.e., Fall 2019), in comparison to limited XR-immersive activities (i.e., Fall 2018). This demonstration of successful implementation of XR-immersive labs creates basis for future research. Future studies should investigate the differences in student motivation to learn in traditional and XR-immersive labs for the KINE 301 course.

\section{CONCLUSION}

This study demonstrates improvement in students' motivation to learn in response to XR-immersive labs in a Motor Control and Learning course in Kinesiology and, therefore, proposes

\section{REFERENCES}

Annamalai, S. (2016). Designing motivating me-book for polytechnic language classroom using ARCS model. Euro. Proceed. Soc. Behav. Sci. 14, 320-326. doi:10.15405/epsbs.2016.08.45

Argles, T., Minocha, S., and Burden, D. (2015). Virtual field teaching has evolved: benefits of a 3D gaming environment. Geol. Today 31 (6), 222-226. doi:10.1111/ gto. 12116

Bennett, J. A., and Saunders, C. P. (2019). A virtual tour of the cell: impact of virtual reality on student learning and engagement in the STEM classroom. J. Microbiol. Biol. Educ. 20, 20.2.37. doi:10.1128/jmbe.v20i2.1658

Bloom, B. (1968). Learning for mastery. Eval. Comment 1, 1-5.

Chang, Y. S., Hu, K. J., Chiang, C. W., and Lugmayr, A. (2019). Applying mobile augmented reality to teach interior design students in layout plans: evaluation of learning effectiveness based on the ARCS model of learning motivation theory. Sensors 20 (1), 105. doi:10.3390/s20010105

Chavez, B., and Bayona, S. (2018). "Virtual reality in the learning process," in Trends and advances in information systems and technologies New York, NY: adaptation of XR-immersive labs as a viable alternative to traditional labs within this field. Finally, our work adds to the exchange of processes for adoption of XR immersion in higher education within the Kinesiology field. Finally, higher mean scores across all dimensions of the IMMS in Fall 2019 may suggest that instructor experience using XR-immersive labs may also positively impact overall efficacy and student motivation to learn.

\section{DATA AVAILABILITY STATEMENT}

The raw data supporting the conclusions of this article will be made available by the authors, without undue reservation.

\section{ETHICS STATEMENT}

The studies involving human participants were reviewed and approved by Institutional Review Board, California State University San Marcos. The patients/participants provided their written informed consent to participate in this study.

\section{AUTHOR CONTRIBUTIONS}

TT: writing-original draft, conceptualization, investigation, methodology, visualization, and formal analysis. $\mathrm{SH}$ : methodology, writing-original draft. JF: writing-reviewing and editing and supervision. PS: data curation, formal analysis, and writing-reviewing and editing supervision.

\section{ACKNOWLEDGMENTS}

The content of this manuscript has been presented in part at the iLRN 2020 Conference and has been indexed by IEEE, ISBN 9781-7348995-0-4/20 (Tunur et al., 2020). We thank (blinded) for the development of the reaching task that was used in this study.

Springer International Publishing, 1345-1356. doi:10.1007/978-3-319-777122_129

Cook, D. A., Beckman, T. J., Thomas, K. G., and Thompson, W. G. (2009). Measuring motivational characteristics of courses: applying Keller's instructional materials motivation survey to a web-based course. Acad. Med. 84, 1505-1509. doi:10.1097/ACM.0b013e3181baf56d

Corbin, J., and Strauss, A. L. (2015). Basics of qualitative research: techniques and procedures for developing grounded theory. 4th Edn. Thousand Oaks, CA: SAGE.

de Vries, L. E., and May, M. (2019). Virtual laboratory simulation in the education of laboratory technicians-motivation and study intensity. Biochem. Mol. Biol. Educ. 47 (3), 257-262. doi:10.1002/bmb.21221

Dede, C. (2008). "Theoretical perspectives influencing the use of information technology in teaching and learning, " in International handbook of information technology in primary and secondary education. Editors J. Voogt and G. Knezek (Boston, MA: Springer), Vol. 20.

Domingo, J. R., and Bradley, E. G. (2018). Education student perceptions of virtual reality as a learning tool. J. Educ. Techn. Syst. 46 (3), 329-342. doi:10.1177/ 0047239517736873 
Eckert, D., and Mower, A. (2020). The effectiveness of virtual reality soft skills training in the enterprise: a study. Available at: https://www.pwc.com/us/ vlearning (Accessed December 27, 2020).

Ericsson, K. A., Krampe, R. T., and Tesch-Römer, C. (1993). The role of deliberate practice in the acquisition of expert performance. Psychol. Rev. 100, 363-406. doi:10.1037/0033-295x.100.3.363

Hartley, M., Ludlow, B., and Duff, M. (2015). Second Life ${ }^{\circledR}$ : a 3D virtual immersive environment for teacher preparation courses in a distance education program. Rur. Spec. Educ. Q. 34 (3), 21-25. doi:10.1177/875687051503400305

Hauze, S. W., Hoyt, H. H., Frazee, J. P., Greiner, P. A., and Marshall, J. M. (2019). Enhancing nursing education through affordable and realistic holographic mixed reality: the virtual standardized patient for clinical simulation. Adv. Exp. Med. Biol. 1120, 1-13. doi:10.1007/978-3-030-06070-1_1

Huang, B., and Hew, K. F. (2016). Measuring learners' motivation level in massive open online courses. Int. J. Inf. Educ. Technol. 6 (10), 759-764. doi:10.7763/ijiet. 2016.v6.788

Janssen, D., Tummel, C., Richert, A., and Isenhardt, I. (2016). Virtual environments in higher education - immersion as a key construct for learning 4.0. Int. J. Adv. Corp. Learn. 9 (2), 20. doi:10.3991/ijac.v9i2.6000

Jensen, L., and Konradsen, F. (2018). A review of the use of virtual reality headmounted displays in education and training. Educ. Inf. Technol. 23, 1515-1529. doi:10.1007/s10639-017-9676-0

Jensen, O. (1998). Buyer-seller-relationships within the international tourism industry. (Original title: kjoeper-selger-relasjoner innenfor internasjonal reiselivsnaering. En studie av samspillet mellom bedriftene ut fra oenske om utvikling av varige konkurransefortrinn). PhD thesis. Aarhus (Denmark): The Aarhus School of Business.

Keller, J. M. (1987). Development and use of the ARCS model of instructional design. J. Instruct. Develop. 10, 2-10. doi:10.1007/bf02905780

Kim, H., and Ke, F. (2016). Effects of game-based learning in an opensimsupported virtual environment on mathematical performance. Inter. Learn. Environ. 25, 543. doi:10.1080/10494820.2016.1167744

Klotz, F. (2018). The quest to create utterly normal virtual reality experiences. MIT Sloan Manag. Rev. 59 (3), 1-5.

Kludge, S., and Riley, L. (2008). Teaching in virtual worlds: opportunities and challenges. Issues Informing Sci. Inf. Technol. 5, 127-135. doi:10.28945/1000

Koglbauer, I. (2015). Training for prediction and management of complex and dynamic flight situations. Procedia Soc. Behav. Sci. 209, 268-276. doi:10.1016/j. sbspro.2015.11.232

Kolb, D. A. (1984). Experiential learning: experience as the source of learning and development. Englewood Cliffs, NJ: Prentice Hall.

Loorbach, N., Peters, O., Karreman, J., and Steehouder, M. (2015). Validation of the instructional materials motivation survey (IMMS) in a self-directed instructional setting aimed at working with technology. Br. J. Educ. Technol. 46, 204-218. doi:10.1111/bjet.12138

Milgram, P., Takemura, H., Utsumi, A., and Kishino, F. (1994). Augmented Reality: a class of displays on the reality-virtuality continuum. SPIE 2351, 282-292. doi:10.1117/12.197321
O'Connor, E. A., and Domingo, J. (2017). A practical guide, with theoretical underpinnings, for creating effective virtual reality learning environments. J. Educ. Technol. Syst. 45 (3), 343-364. doi:10.1177/0047239516673361

Radianti, J., Majchrzak, T. A., Fromm, J., and Wohlgenannt, I. (2020). A systematic review of immersive virtual reality applications for higher education: design elements, lessons learned, and research agenda. Comput. Educ. 147, 103778. doi:10.1016/j.compedu.2019.103778

Rae, A., and Samuels, P. (2011). Web-based Personalised System of Instruction: an effective approach for diverse cohorts with virtual learning environments? Comput. Educ. 57 (4), 2423-2431. doi:10.1016/j.compedu.2011.06.003

Riva, G. (2016). Embodied medicine: what human-computer con-fluence can offer to health care. Hum. Comput. Conflu.: Transfo. Hum. Exp. Throu. Symb. Tech. 181, 55-78. doi:10.1515/9783110471137-004

Sattar, M. U., Palaniappan, S., Lokman, A., Hassan, A., Shah, N., and Riaz, Z. (2019). Effects of virtual reality training on medical students' learning motivation and competency. Pak J. Med. Sci. 35 (3), 852-857. doi:10.12669/pjms.35.3.44

Shuell, T. J. (1986). Cognitive conceptions of learning. Rev. Educ. Res. 56 (4), 411-436. doi:10.3102/00346543056004411

Siemens, G. (2005). Connectivism: a learning theory for the digital age. Int. J. Instruct. Technol. Dist. Learn. 2, 1-8.

Stake, R. E. (1995). The art of case study research. Thousand Oaks, CA: SAGE Publications.

Stepan, K., Zeiger, J., Hanchuk, S., Del Signore, A., Shrivastava, R., Govindaraj, S., et al. (2017). Immersive virtual reality as a teaching tool for neuroanatomy. Int. Forum Allergy Rhinol. 7 (10), 1006-1013. doi:10.1002/alr.21986

Tunur, T., Hauze, S. W., Stuhr, P. T., and Frazee, J. P. (2020). Work-in-progress paper: the impact of kinesiology XR-immersive labs for motor control learning attitudes. Proceedings, 6th International Conference of the Immersive Learning Research Network (iLRN), San Luis Obispo, CA, June 21-25, 2020, New York, NY: IEEE.

Urso, P., and Fisher, L. (2018). Education technology to service a new population of e-learners. Int. J. Childbirth Educ. 30 (3), 33-36. doi:10.1177/ 0047239517736873

Walmart Case Study (2018). In the footsteps of trailblazers: How Walmart embraces Immersive Learning. Available at: https://www.strivr.com/ resources/customers/walmart/ (Accessed December 27, 2020).

Conflict of Interest: The authors declare that the research was conducted in the absence of any commercial or financial relationships that could be construed as a potential conflict of interest.

Copyright (c) 2021 Tunur, Hauze, Frazee and Stuhr. This is an open-access article distributed under the terms of the Creative Commons Attribution License (CC BY). The use, distribution or reproduction in other forums is permitted, provided the original author(s) and the copyright owner(s) are credited and that the original publication in this journal is cited, in accordance with accepted academic practice. No use, distribution or reproduction is permitted which does not comply with these terms. 